\title{
Projeto Equinócios: Intervenção Junto à População em Situação de Rua
}

\section{Proyecto Equinoccios: Intervención con la Población en Situación de Calle}

\author{
Equinoxes Project: Intervention with the Homeless Population
}

\author{
Centro Universitário do Distrito Federal (UDF), Brasília - DF/Brasil \\ ORCID: 0000-0002-5927-6429 \\ E-mail: juliana.sangoi@gmail.com
}

André Luís Ferreira Moniz
Centro Universitário do Distrito Federal (UDF), Brasília - DF/Brasil
ORCID: 0000-0002-2754-9437
E-mail: monizudf@gmail.com

Carolina Conceição Prado

Centro Universitário do Distrito Federal (UDF), Brasília - DF/Brasil ORCID: 0000-0003-4247-0695

E-mail: carolcprado@hotmail.com

\begin{abstract}
Resumo
Este estudo analisou o impacto do Projeto Equinócios que ofereceu à população em situação de rua oficinas artísticas, terapêuticas, educacionais e profissionalizantes, a partir da perspectiva dos Profissionais do Centro de Referência Especializado para População em Situação de Rua - Centro POP Brasília DF e usuários do serviço. Para isso, foram realizadas observações, entrevistas semiestruturas e questionários com 20 indivíduos da população em situação de rua, 08 funcionários do Centro POP e 04 oficineiros, professores que ministraram as oficinas. Os resultados mostraram que o Projeto Equinócios possui relevância no empoderamento da população em situação de rua, propiciando a abertura de espaços para o resgate da identidade e a realização de processos em que os sujeitos empoderam a si mesmos. Estimulou a criação de vínculos de colaboração e solidariedade dentre eles e a comunidade residente na cidade de Brasília, promovendo o aprimoramento das vivências comunitárias e do sentimento de pertencimento mútuo, contribuindo diretamente na promoção da saúde de seus frequentadores. Conclui-se que o Projeto Equinócios promoveu a união e o diálogo entre instituições públicas e a sociedade civil, possibilitando o desenvolvimento de estratégias integradas e multidisciplinares às políticas públicas para pessoas em situação de rua.
\end{abstract}

Palavras-chaves: Pessoas em situação de rua; Promoção da saúde; Política Pública.

\section{Resumen}

Este estudio analizó el impacto el Proyecto Equinoccios, que ofreció a la población que vive en la calle talleres artísticos, terapéuticos, educativos y profesionales desde la perspectiva de los Profesionales del Centro de Referencia Especializado para Personas en Situación de Calle - Centro POP Brasilia DF y usuarios del servicio. Para ello, se llevaron a cabo observaciones, entrevistas semiestructuradas y cuestionarios con 20 personas de la población que viven en las calles, 08 empleados del Centro POP y 04 trabajadores de talleres, maestros que impartieron los talleres. Los resultados mostraron que el Proyecto Equinócios tiene relevancia en el empoderamiento de la población sin hogar, proporcionando la apertura de espacios para el rescate de la identidad y la realización de procesos en los que los sujetos se empoderan a sí mismos. Estimuló la creación de vínculos de colaboración y solidaridad entre ellos y la comunidad que vive en la ciudad de Brasilia, promoviendo la mejora de las experiencias de la comunidad y el sentimiento de pertenencia mutua, contribuyendo directamente a la promoción de la salud de sus clientes habituales. Se concluye que el Proyecto Equinócios promovió la unión y el diálogo entre las instituciones públicas y la sociedad civil, permitiendo el desarrollo de estrategias integradas y multidisciplinarias de políticas públicas para las personas en las calles.

Palabras clave: Personas en situación de calle; Promoción de la salud; Política Pública. 


\begin{abstract}
This study analyzed the impact of the Equinoxes Project, which offered the homeless population artistic, therapeutic, educational and professional workshops, from the perspective of the Professionals of the Specialized Reference Center for the Homeless Population - Centro POP Brasília DF and users of the service. For this, observations, semi-structured interviews and questionnaires were carried out with 20 individuals from the homeless population, 08 employees from the Centro POP and 04 workshop workers, teachers who gave the workshops. The results showed that the Equinoxes Project has relevance in the empowerment of the homeless population, providing the opening of spaces
\end{abstract}

\section{Introdução}

A discussão em torno das políticas públicas direcionadas às pessoas que vivem em situação de rua está inserida dentro de debates mais amplos sobre exclusão social, suscitando calorosos diálogos entre diversos setores da sociedade brasileira e internacional. Escorel (1999) compreende como exclusão social do ser humano os processos de fragilização, vulnerabilidade e ruptura dos vínculos sociais, em cinco dimensões: ocupacional, familiar, política, cultural e da saúde.

Segundo Gama, Campos e Ferrer (2014), a vulnerabilidade social é a incapacidade que o indivíduo tem, de responder ao ambiente para lidar com as circunstâncias, tendendo a experimentar consequências negativas devido à falta de representatividade $\mathrm{e}$ de oportunidades. Está relacionada as possibilidades de deterioração do ser humano diante das situações do dia a dia. Não é uma condição que dependa apenas do indivíduo, mas também de intrincados agentes externos, que geram uma condição de fragilidade. Para Sánchez e Bertolozzi (2007), a vulnerabilidade social se relaciona com a discriminação ou enfraquecimento dos grupos sociais e sua baixa capacidade de reação aos eventos cotidianos.

As mudanças e avanços, no que tange aos direitos da População em Situação de Rua são recentes, e faz-se necessário que a sociedade perceba e compreenda que tal população é um grupo social com direito ao trabalho, à habitação, à educação e à cultura. Segundo Pereira (2008), a pobreza no Brasil for the rescue of identity and the realization of processes in which the subjects empower themselves. It stimulated the creation of bonds of collaboration and solidarity between them and the community living in the city of Brasilia, promoting the improvement of community experiences and the feeling of mutual belonging, directly contributing to the promotion of the health of its visitors. It is concluded that the Equinoxes Project promoted the union and dialogue between public institutions and civil society, enabling the development of integrated and multidisciplinary strategies to public policies for people on the streets.

Keywords: Homeless, Health promotion; Public Policy. nunca foi considerada prioridade governamental, pelo contrário, sempre foi condicionada aos escassos recursos disponíveis e, por isso, alvo de atendimentos emergenciais e precários, sem qualquer planejamento. Para que haja uma mudança efetiva em relação aos direitos desses sujeitos políticos, deve haver um esforço da sociedade em si e dos governos que a servem, objetivando o desenvolvimento de estratégias integradas e multidisciplinares.

Para Akerman, Franco de Sá, Moyses, Rezende e Rocha (2014), a População em Situação de Rua, em meio à desigualdade política e social em que está inserida, encontrou a força necessária para se constituir em sujeitos políticos, frente a exclusão e marginalização, empoderando-se em suas cidadanias. Para o atendimento à essa população é necessário compreendê-la em sua totalidade, considerando suas necessidades individuais e coletivas, construindo políticas públicas que reconheçam a sua importância social.

Segundo o Decreto n ${ }^{\circ} 7.053 / 2009$, “a população em situação de rua caracteriza-se por ser um grupo populacional heterogêneo que possui em comum a pobreza extrema, os vínculos fragilizados ou rompidos $\mathrm{e}$ a inexistência de moradia convencional regular" (p.16).

Em Pontes (2009), a população em situação de rua é tida como:

um segmento composto por sujeitos de direitos - como qualquer outro cidadão deste país - o presente 
escrito parte do princípio de que as pessoas na rua são transformadas em um grupo político "invisível”, em descartáveis urbanos, resultando na desconsideração de suas respectivas demandas e evidenciando a ausência do Estado e uma relação de (não) proteção por parte deste. (Pontes, 2009. p. 10).

Segundo Frangella (2009), a presença de pessoas em situação de rua no Brasil está diretamente conectada ao processo histórico, que vem desde o início da urbanização e da industrialização do País, com a divisão social e o surgimento de duas novas classes sociais antagônicas: a burguesia e o proletariado.

Pode-se relacionar o fenômeno da População em Situação de Rua diretamente às políticas de higienização social, com o capitalismo propriamente dito. Nas práticas "higienistas", a desorganização social e o mau funcionamento da sociedade eram consideradas causas de doenças, cabendo à área de saúde intervir para anular perigos eminentes e atuar sobre os elementos naturais, urbanísticos e institucionais (Paiva, Lira, Justino, Miranda, \& Saraiva, 2016). Assim, a população desabastecida e carente passou a ser considerada um problema social de massa, destinada a viver em favelas, em lugares ermos ou periféricos e nas ruas.

Segundo Hino, Santos e Rosa (2018), a construção de propostas para o cuidado da População em Situação de Rua possui longo histórico de intersetorialidade, começando na década de 70 do século passado com a Pastoral do Povo da Rua, grupo da Igreja Católica romana. As iniciativas religiosas eram responsáveis por implantar casas de assistência social direcionadas ao atendimento de pessoas que viviam nas ruas.

De acordo com a Secretaria de Direitos Humanos da Presidência da República (Brasil, 2013), foi a partir de 2005, por intermédio do Ministério de Desenvolvimento Social e Combate à Fome (MDS) que se iniciou, sem precedentes na história de nosso País, uma discussão sobre o fenômeno social das pessoas em situação de rua. Foram então criadas diversas iniciativas que possibilitaram que a sociedade interviesse e que colaborasse na construção de políticas públicas direcionadas à População em Situação de Rua. Porém, somente em 2009 viu-se a importância de se instituir a Política Nacional para População em Situação de Rua.

Consoante com o Ministério da Saúde (Brasil, 2014), anterior à instituição de tal política pública, em 2009, embora existissem ações do Estado e da sociedade, preocupandose com essa população, as práticas eram sempre sob o olhar do assistencialismo.

De acordo com o Ministério do Desenvolvimento Social e Combate à Fome (MDS) (Brasil, 2008b), que assumiu o compromisso de formular políticas públicas para a População em Situação de Rua, Brasília, $\mathrm{DF}$, foi a primeira unidade da Federação a aderir à política nacional para essa população, até então "invisível".

Segundo Mattos e Ferreira (2004), é comum se deparar, no cotidiano da maioria das capitais brasileiras, com a figura desse sujeito político, pessoa em situação de rua, uma vez que ele habita, com frequência, espaços públicos. Portanto, é fácil supor que de alguma forma há contato das pessoas em situação de rua com o restante da sociedade: no trânsito, na frente das casas, nas praças, nos estacionamentos. Contudo, há preconceitos e discriminações nesses "encontros", devido a discrepâncias nas vestimentas e nas condições higiênicas da População em Situação de Rua, e outros constrangimentos perante ela. Nesse caso, é visível a percepção de que as representações sociais sobre as pessoas em situação de rua reforçam a construção de estigmas e a formação de rótulos em relação a esses anônimos.

A partir da singularidade em que se constitui Brasília, uma capital planejada, com espaços amplos e uma dinâmica política e econômica que apresenta uma das rendas per capita mais altas do Brasil, mas com baixa 
distribuição, a presença de pessoas em situação de rua é menos visível. Nela existem 1,08 milhão de veículos automotores rodoviários, segundo o Departamento Nacional de Trânsito (2015), e é comum aos cidadãos, nos deslocamentos que fazem nesses veículos, não olharem para os lados, nem quando momentaneamente param nos trajetos que seguem. É comum não se observar pessoas nas ruas, o que dificulta a interação social e aumenta o estigma das pessoas em situação de rua.

Pereira (2008), quando se refere à Brasília, mostra que na Capital federal esse grupo social, pessoas em situação de rua, possui características únicas e específicas em relação aos outros entes federados. Em Brasília, grande parte da População em Situação de Rua é constituída de imigrantes, que enxergaram essa capital como um espaço propício para adquirir melhores condições de vida, e que, são, em sua maioria, trabalhadores: $21,3 \%$ são flanelinhas, $19,3 \%$ trabalham com reciclagem e $12,3 \%$ trabalham informalmente em construção civil. Apenas $10,6 \%$ dos moradores de rua declararam que vivem de esmola.

Pereira (2008) também identificou, nesse estudo, que em Brasília há três tipos de grupos de pessoas em situação de rua: a) os que residem no entorno do Distrito Federal, nas cidades vizinhas, mas que em épocas festivas, como Natal e Ano Novo, montam suas barracas nas ruas e praças objetivando receber doações dos transeuntes e que, terminadas as comemorações, retornam às suas cidades; b) os que vêm à Capital federal em busca de emprego e que, não encontrando, deixam de retornar às suas origens por falta de recursos; e c) os que trabalham no Plano Piloto e moram em barracos, construídos em locais ermos, onde quase ninguém os vê, tornando-se desconhecidos, diferentemente de outros centros urbanos como São Paulo e Rio de Janeiro, nos quais grande parte da população de rua, para proteger a vida, escolhe lugares muito movimentados para viver, pois sente medo de ser assassinada. Viver na rua é estar exposto a doenças, à insegurança, à falta de higiene e à violência, por parte de cidadãos com residência regular e fixa, da polícia ou mesmo de outras pessoas em situação de rua (Pereira, 2008).

Dessarte, com a ideia de criação de vínculos e de um projeto construído em parceria com a população que vive nas ruas de Brasília - DF, surgiu, no ano de 2015, o Projeto Equinócios: atividades em comunidade, formado por um coletivo de artistas da cidade, instituindo pela primeira vez um projeto social, ambiental e artístico dentro de uma Unidade de Referência Especializada para População em Situação de Rua - Centro POP.

O Centro de Referência Especializado para População em Situação de Rua - Centro POP Brasília (Brasil, 2011b), constitui-se em uma unidade de referência de proteção social, de caráter público estatal, com papel importante no alcance dos objetivos da Política Nacional para a População em Situação de Rua, tendo a sua condução sob a responsabilidade do órgão gestor da Política Nacional de Assistência Social (PNAS) no Distrito Federal, a Secretaria de Estado de Trabalho, Desenvolvimento Social, Mulheres, Igualdade Racial e Direitos Humanos (SEDESTMIDH).

O Centro POP Brasília se propõe a desenvolver relações de solidariedade, afetividade e respeito. Trata-se de um espaço destinado às pessoas que vivem em situação de rua, com a finalidade de assegurar a essas pessoas o acompanhamento especializado de suas vidas e de as viabilizar o gradativo processo de saída da situação de rua. $\mathrm{Na}$ unidade do Centro POP Brasília as pessoas que vivem em situação de rua podem acessar os seus direitos socioassistenciais, que lhes são assegurados pela Lei $\mathrm{n}^{\circ} 8.742$, de 7 de dezembro de 1993, e que e se constituem num conjunto de ações integradas, de iniciativa pública e da sociedade, para garantir o atendimento às suas necessidades básicas, como tomar banho, lavar roupas, alimentar-se e guardar seus pertences (Hino, Santos \& Rosa, 2018).

O Projeto Equinócios foi idealizado pela sociedade civil e construído a partir de vínculos e diálogos com a população em 
situação de rua usuária do Centro POP Brasília, com o intuito de resgatar as memórias afetivas por intermédio da arte e da cultura, de paulatinamente integrar a população em vulnerabilidade $^{1}$ (População em Situação de Rua) à sociedade normalmente definida, e de possibilitar o diálogo e a visibilidade sobre a real situação desse novo sujeito político pelo desenvolvimento de vínculos entre todos os envolvidos: gestores de programas públicos, sociedade, governantes e população em situação de rua. Esse projeto foi financiado pelo FAC (Fundo de Apoio à Cultura) da Secretária de Cultura do Distrito Federal (SECULT) e possui parceria com a SEDESTMIDH, com a Secretaria de Educação do Governo do Distrito Federal (SEDF) e com a Secretária de Saúde do Governo do Distrito Federal (SES).

Este estudo objetivou fazer uma análise do impacto social do Projeto Equinócios, fundada na observação e realização de oficinas para a população em situação de rua, buscando responder a hipótese norteadora: de que forma a implementação de um programa de intervenção artística, social e comunitária junto à população de rua do Distrito Federal poderia contribuir para a reversão dos problemas enfrentados por órgãos públicos, pela comunidade envolvida e pelas próprias pessoas em situação de rua.

\section{Metodologia}

O presente projeto de intervenção, de natureza qualitativa, enfatiza o ponto de vista dos sujeitos, incluindo a dimensão subjetiva nas análises sociais. Dessarte, foram utilizados diferentes roteiros de entrevistas semiestruturadas para os três grupos pesquisados; 1) população em situação de rua atendido pelo Centro POP Brasília, com intuito de identificar e caracterizar os elementos psicológicos relativos à subjetividade da

\footnotetext{
1 Vulnerabilidade: A concepção de vulnerabilidade denota a multideterminação de sua gênese não estritamente condicionada à ausência ou precariedade no acesso à renda, mas atrelada também às fragilidades dos vínculos afetivo-relacionais e às desigualdades de acesso a bens e serviços públicos. (Carmo \& Guizardi, 2018, p. 2).
}

população de rua e de avaliar a execução das oficinas; 2) profissionais do Centro POP Brasília, com intuito de caracterizar os desafios enfrentados no cotidiano do trabalho desenvolvido junto à população em situação de rua; e 3) profissionais contratados para ministrar as oficinas do Projeto Equinócios, com objetivo de identificar como foi a experiência de trabalhar junto à população em situação de rua, visto que nenhum deles havia tido tal experiência profissional até então.

Para a pesquisa utilizou-se, também, o diário de campo, no qual constam anotações diárias, do início do projeto, em outubro de 2015, até junho de 2016. Foram anotadas questões de execução e de logística do projeto, assim como registrados depoimentos de todos envolvidos. As entrevistas foram realizadas ao final de cada uma das oficinas.

Para os dados frutos de observações, foram feitas fichas de observações in loco para as três oficinas realizadas. Cada uma das oficinas teve a carga horária de 136 horas e as três aconteceram em 6 meses corridos. Foram fornecidas as listas de participantes de cada aula/oficina, para que fosse possível mensurar a frequência dos "alunos" no decorrer do Projeto Equinócios.

O presente estudo foi realizado com a participação de 32 pessoas: servidores do Centro POP Brasília $(\mathrm{N}=8)$; profissionais contratados para ministrar as oficinas $(\mathrm{N}=4)$; indivíduos da população em situação de rua $(\mathrm{N}=20)$;). Foi implementado pelos profissionais do Centro POP Brasília e pelos oficineiros (contratados) do Projeto Equinócios, sob supervisão de um coordenador.

A entrevista com os profissionais do Centro POP Brasília se deu por intermédio de roteiro semiestruturado com quinze 
perguntas abertas. Para os profissionais contratados para realizar as oficinas do Projeto Equinócios, a entrevista semiestruturada contou com vinte (20) perguntas, sendo dez (10) abertas e cinco (5) fechadas.

As entrevistas semiestruturadas com as vinte pessoas da população em situação de rua foram realizadas em grupo, contendo um roteiro de quinze (15) perguntas, oito (8) abertas e sete (7) fechadas, sendo que doze (12) perguntas com o intuito de: identificar a rotina quanto ao modo como elas são tratadas pela comunidade que as envolve; as suas formas de diversão; as estratégias que adotam quando não se sentem bem; se frequentam ou não, abrigos noturnos; os elementos que mais gostam e os que menos gostam em suas vivências em situação de rua; os motivos que as levaram a tal condição; etc. E as outras três (3) perguntas foram referentes às oficinas realizadas, identificando qual foi o impacto do Projeto Equinócios na vida delas. $\mathrm{O}$ grupo foi conduzido a um ambiente silencioso que permitia sigilo às informações. As entrevistas semiestruturadas e os questionários foram aplicados, contando com a participação da pesquisadora/coordenadora e de dois mediadores/facilitadores, uma (1) psicóloga e uma (1) educadora social, servidores do Centro POP Brasília. A participação dessas duas específicas servidoras públicas na pesquisa se deu pelo fato de elas possuírem forte $\mathrm{e}$ significativo vínculo afetivo com os usuários do Centro POP Brasília e, também, para que, acaso houvesse algum analfabeto dentre os vinte participantes, auxiliassem esses possíveis iletrados, particular e sigilosamente (lendo novamente a questão, facilitando a compreensão textual da questão). As entrevistas foram realizadas ao final de cada oficina, entre março e maio de 2016, totalizando entre anotações de observação e aplicação de entrevistas/questionários, 6 meses de coleta de dados.

Para participar do estudo foram considerados como critérios de inclusão: pessoas em situação de rua de ambos os sexos, com idade acima de 18 anos e que frequentaram pelo menos uma das oficinas propostas e que estiveram dispostas a participar da pesquisa voluntariamente. Para o objetivo de implementação das oficinas terapêuticas junto à população atendida, foram utilizadas fichas de observação e o diário de campo da coordenadora do Projeto Equinócios.

Foram implementadas as seguintes oficinas terapêuticas, artísticas e sociais pelo Projeto Equinócios: a) oficina de agroecologia (horticultura e jardinagem): oficina de caráter prático, integrando-se às atividades de implementação/manutenção de horta, abordando aspectos ambientais, alimentares, econômicos, culturais e de cidadania. A oficina foi dividida em 2 aulas semanais de 3 horas aulas, cada, nas terças e quartas-feiras; b) oficina de arte gráfica urbana (estêncil, mural e grafite): por intermédio dessa oficina os atendidos tiveram contato com técnicas e linguagens que trazem um olhar positivo e construtivo em relação ao espaço urbano e que ampliam as ferramentas expressivas dos atendidos. A oficina foi dividida em 2 aulas semanais de 3 horas aulas, cada, nas quintas e sextas-feiras; e c) oficina de fotografia e de formação de memória imagética: nessa, abordou-se a constituição de memória pela fotografia, trazendo a oportunidade do registro do cotidiano aos atendidos, a partir de suas próprias percepções. A oficina foi dividida em 1 aula semanal de 4 horas aulas, cada, sempre às segundas-feiras.

Para a realização da pesquisa foi necessária a autorização da SEDESTMIDH e do auxílio de uma (1) psicóloga e de uma (1) educadora especializada em atividades de rua, servidoras do Centro POP Brasília. A participação dessas duas específicas servidoras públicas na pesquisa se deu, como dito, em face de seus entrosamentos afetivos com os usuários do Centro POP Brasília. Todos os procedimentos de coletas de dados foram realizados no Centro POP Brasília, em uma sala reservada.

Esse trabalho foi orientado pela Resolução n. ${ }^{\circ}$ 196/1996 do Conselho Nacional de Saúde e considerou as Diretrizes e Normas Regulamentadoras de Pesquisas Envolvendo 
Seres Humanos, buscando manter os direitos da pessoa pesquisada a partir da correta conduta ética dos pesquisadores e da aplicação do Termo de Consentimento Livre e Esclarecido (TCLE) proposto pelo Comitê de Ética em Pesquisa - CEP competente, Parecer de Aprovação n ${ }^{\circ} 1127231$.

Os dados qualitativos do estudo em questão foram coletados e analisados em seu conteúdo. Foram consideradas as entrevistas dos indivíduos da população em situação de rua, da equipe do Projeto Equinócios e dos servidores do Centro POP Brasília. Para essa análise, também foram consideradas as observações registradas pela pesquisadora/coordenadora em seu diário de campo. Os dados foram analisados por semelhança e conteúdo, de acordo com o referencial teórico das diretrizes que nortearam esta pesquisa: Moniz, 2014; Gatti e Pereira, 2011; e Pesquisa Nacional sobre a População em Situação de Rua (Brasil, 2008b).

A interpretação dos resultados da pesquisa foi elaborada com base nos dados qualitativos coletados nas entrevistas semiestruturadas, verificando-se significativa correlação entre eles e as referências teóricas e históricas que fundamentaram a investigação. Nesse processo, subjetivo como todo processo que trabalha com dados não parametrizados, fez-se também o uso de dados coletados em observações de campo.

\section{Resultados e discussão}

O Projeto Equinócios, de caráter social, foi idealizado com intuito de levar às pessoas em situação de rua um diálogo sobre arte e cultura. O objetivo de tal projeto foi de integrar a população em vulnerabilidade aos gestores de programas sociais, à sociedade e aos governos de todas as esferas de poder. Dessarte, tratou-se de uma iniciativa voluntária de dois jovens residentes na cidade de Brasília, DF, que, com um olhar diferenciado, propuseram-se a levar aos cidadãos brasilienses uma nova forma de compreender a subjetividade da População em Situação de Rua, na tentativa de criar vínculos permanentes e de contribuir para a construção de uma comunidade mais humanizada.

Foi uma proposta artística e social de longa duração (16 meses) que ofereceu, às pessoas em situação de rua, oficinas artísticas, terapêuticas, educacionais e profissionalizantes. A intenção mor do projeto foi resgatar a potencialidade de cada um desses cidadãos, por intermédio da arte. As oficinas artísticas do Projeto Equinócios iniciaram-se em outubro de 2015 e se desenvolveram no Centro POP Brasília e em espaços urbanos da cidade de Brasília, buscando a integração dessa comunidade com o todo, sociedade, até maio de 2017, por meio do financiamento do FAC. As oficinas artísticas foram oferecidas aos usuários dos serviços prestados pelo Centro POP Brasília.

Durante os 16 meses em que o Projeto Equinócios aconteceu, 6 meses acompanhados por essa pesquisa, pôde-se observar aumento da procura das redes de saúde, de educação e de cultura pelas pessoas em situação de rua, assim como o fortalecimento do restante da sociedade em relação à promoção da saúde e dos direitos das pessoas em situação de rua, atuando diretamente em prol da redução de danos aos usuários de substâncias psicoativas e na elevação da autoestima desse segmento populacional.

Segundo Vitoriano (2011), ações integradas entre a sociedade e o poder público, realizando uma rede de proteção social para a população em situação de rua, fortalecem as políticas públicas que buscam enfrentar a problemática social da pobreza e das desigualdades sociais, frente à necessidade da demanda e à escassez de recursos.

Segundo os servidores do Centro POP Brasília, o Distrito Federal (DF) conta com uma ampla rede de serviços para atender a População em Situação de Rua. Essa rede compreende um conjunto de serviços públicos e da sociedade, que se entrelaçam e se organizam numa disposição tal que são capazes de atender os indivíduos e os grupos em suas mais variadas necessidades (Ministério do 
Desenvolvimento Social e Combate à Fome, 2013). Nesse contexto, destacam-se: (1) A Política de Assistência Social do Distrito Federal, com o projeto de enfretamento da pobreza e o projeto de implementação da Política para Inclusão da Pessoa em Situação de Rua, dentre outras ações; (2) Serviço de Abordagem Social, composto por equipes de educadores sociais de rua que realizam abordagens sociais e buscas ativas, acompanhando os usuários aos serviços da rede, como saúde, assistência social, moradia, defensoria pública, trabalho, documentação civil, educação, cultura e órgãos do poder judiciário; (3) Centro de Referência Especializado para População em Situação de Rua; (4) Centro de Referência Especializado da Assistência Social (CREAS), o qual atende famílias e indivíduos que se encontram em situação de vulnerabilidade social e que necessitam de atenção especializada; e (5) Centro de Referência da Assistência Social (CRAS), onde são desenvolvidas ações com o intuito de proteção social; acolhida e recepção; escuta e encaminhamentos; oficinas de geração de renda e atividades coletivas.

A Política de Assistência Social divide-se em duas formas de proteção: básica e especial. A proteção social básica objetiva prevenir situações de risco, fortalecendo vínculos familiares, afetivos e comunitários de indivíduos em situação de pobreza. Ao contrário da proteção básica, de caráter preventivo, a proteção social especial é destinada a proteger indivíduos e famílias que já se encontram em situação de violação de direitos e de risco pessoal e social, tais como: violência física ou psicológica; abuso sexual; uso de álcool e de outras drogas; trabalho infantil; situação de rua; abandono; etc. Essas ações exigem acompanhamento dos indivíduos e das famílias atendidas, monitoramento dos encaminhamentos e apoio aos serviços e processos que garantam a recuperação dos vínculos perdidos por essa clientela e o respeito aos seus direitos. Os Centros de Referência Especializados de Assistência Social (CREAS) são as unidades públicas que oferecem proteção social especial por meio de serviços gratuitos a esses indivíduos e famílias. (Gatti \& Pereira, 2011, p.21).

O Projeto Equinócios aconteceu no Centro POP Brasília, que é subordinado à SEDESTMIDH (Brasil, 2011a), responsável pela execução das políticas de Assistência Social, Transferência de Renda e de Segurança Alimentar e Nutricional; pela gestão do Sistema Único de Assistência Social; e pelo Sistema Nacional de Segurança Alimentar e Nutricional no âmbito do DF.

O Centro POP Brasília é um espaço destinado às pessoas que vivem em situação de rua, com a finalidade de assegurar acompanhamento especializado, viabilizando o processo gradativo de saída da situação de rua. Conforme a legislação (Brasil, 2011b), a sua equipe de profissionais é multidisciplinar, contando com um (1) coordenador; dois (2) assistentes sociais; dois (2) psicólogos; um (1) técnico de nível superior, preferencialmente com formação em direito, pedagogia, antropologia, sociologia ou terapia ocupacional; quatro (4) técnicos de nível superior ou de nível médio para a realização do Serviço Especializado em Abordagem Social (quando ofertada pelo Centro POP Brasília) ou para o desenvolvimento de oficinas socioeducativas; e dois (2) auxiliares administrativos. Na unidade de acolhimento propriamente dita, as pessoas que vivem em situação de rua podem acessar os seus direitos socioassistenciais, assim como tomar banho, lavar roupas, alimentar-se e guardar seus pertences.

De acordo com a legislação (Brasil, 2011b), a Unidade de Acolhimento (Centro POP) prevê uma estrutura básica de 12 (doze) servidores para atender até 100 usuários/dia. Todavia, conforme observado e relatado pelos servidores que compõe o corpo técnico do Centro POP Brasília, a unidade, à época da pesquisa, funcionava com apenas $10(\mathrm{dez})$ 
servidores, para atender a demanda de 140 a 200 usuários/dia. Durante o período de coleta de dados somente foi possível entrevistar 8 (oito) servidores que fazem parte da equipe do Centro POP Brasília, pelo fato de que os outros dois (2) encontravam-se em gozo de licença médica.

À época, encontravam-se no Centro POP Brasília um (1) agente social; um (1) assessor de comunicação; um (1) educador social de rua; três (3) técnicos de nível superior com formação em psicologia; (1) um coordenador; e um (1) profissional de nível básico. Os 8 (oito) servidores em questão eram responsáveis pelo atendimento de 140 a 200 usuários, o que tornava o êxito de tal demanda duvidoso e extremamente cansativo, visto que as ações aplicadas exigem acompanhamento dos indivíduos, monitoramento dos encaminhamentos e apoio aos serviços e processos que garantam a recuperação dos vínculos sociais perdidos e o direito à informação de forma esclarecida.

Segundo Bonalume (2011), embora as diretrizes da Política Nacional para Inclusão da População em Situação de Rua esteja presente desde 2008, ainda há fragmentações nas ações voltadas a esse segmento, uma vez que os governos não seguem as diretrizes de gestão dos serviços, o que diminui a eficiência de suas abrangências para a assistência integral e eficaz aos usuários.

Nos meses em que o Projeto Equinócios foi observado ocorreram reuniões de equipe do Centro POP Brasília e de estudo de casos dos usuários, assim como funcionou o "Consultório na Rua". Percebeu-se o adoecimento frequente dos profissionais de atendimento, em face de frustração e estresse, por não conseguirem atender de forma plena todos que os buscavam, sendo de 20 a 30 a média de atendimentos individuais diários para cada servidor.

Além da redução do tamanho da equipe, havia muitas queixas advindas da própria estrutura de trabalho. Queixaram-se da burocracia do sistema, que não permitia que se executasse os serviços com presteza; da precariedade da estrutura física da unidade de atendimento; da falta de servidores perante a demanda; e das limitações de recursos básicos para o funcionamento da unidade, como produtos de higiene e alimentação adequada para os usuários. Porém, disseram fazer o trabalho da forma mais criativa possível, para que os usuários não se sentissem prejudicados, relatando que encaravam a profissão como um importante compromisso social.

De acordo com Brasil (2013) para a melhoria do atendimento à população em situação de rua deve-se desenvolver políticas de valorização dos trabalhadores e melhorias das condições de trabalho nos espaços de acolhida dessa população, para que as políticas públicas voltadas a esse público sejam realmente efetivas.

Dessarte, os servidores do Centro POP Brasília relataram que o Projeto Equinócios promoveu a integração da equipe de servidores com a população em situação de rua atendida, de forma que a promoção da saúde e a da educação social fluiu melhor, reduzindo significativamente os índices de violência dentre a população em situação de rua, na unidade de atendimento. Segundo os entrevistados, a visibilidade do Projeto Equinócios e as ações positivas realizadas dentro da unidade de atendimento possibilitaram convites de outras organizações públicas e privadas, visando introduzir a População em Situação de Rua em atividades além do campo de ação do Centro POP Brasília.

Outro dado coletado nas entrevistas com os servidores do Centro POP Brasília, de extrema relevância, foi a constatação de que, através da arte e da participação de outras pessoas que não servidores públicos na unidade (artistas, voluntários, equipe do Projeto Equinócios), o estado de espírito da população em situação de rua mudou, propiciando mais receptividade e predisposição a diálogos. Os servidores relataram, ainda, que, a partir das oficinas, a população em situação de rua passou a compartilhar dados afetivos de suas histórias de vida, nos atendimentos individuais, aumentando o vínculo entre todos. Segundo o 
Ministério do Desenvolvimento Social e Combate à Fome (Brasil, 2011b), faz-se necessário a criação de vínculos de confiança entre os usuários do Centro POP e os profissionais que prestam serviço no local, para que efetivamente haja atendimento integral a essa população. Seguindo a mesma linha, para Brasil (2013) um projeto que busca a construção de sujeitos autônomos, deve promover a formação de vínculo e acolhimento entre todos os envolvidos, reconhecendo a pessoa em situação de rua como um sujeito com demandas e necessidades próprias.

$\begin{array}{rcrr}\text { Identificou-se que } & \text { o fator mais } \\ \text { estressante, segundo } & \text { os } & \text { servidores }\end{array}$ entrevistados, foi o fato de eles trabalharem com incertezas, haja vista as flutuações das políticas públicas no País, notadamente quanto a recursos orçamentários e financeiros no campo do atendimento social. Isso se coaduna com os estudos de Brisola (2016), que identificou, nos profissionais da assistência social do Sistema Único de Assistência Social - SUAS, ao qual o Centro POP faz parte, insegurança no trabalho, falta de estabilidade, demandas acima do cumprimento de metas, burocratização do serviço e ausência de capacitações para a realização do serviço, dentre outros problemas laborais.

Quanto às entrevistas dos 4 professores (oficineiros) contratados para ministrar as oficinas no Centro POP Brasília, 3 relataram estarem satisfeitos com o trabalho, sentindo-se motivados com a transformadora experiência. $\mathrm{O}$ outro entrevistado relatou que, apesar da motivação social, trabalhar com a População em Situação de Rua $^{2}$ era extremamente frustrante, visto que o grupo atendido não mantinha a organização esperada pelo profissional dentro do espaço destinado às aulas ou oficinas. O entrevistado solicitou ajuda terapêutica e, após cumprir a carga horária acordada, se retirou do projeto, não participando das atividades subsequentes.

\footnotetext{
2 População em Situação de Rua, com letras maiúsculas, significa toda essa população. Com letras minúsculas, subconjunto daquela.
}

Nenhum dos profissionais contratados para ministrar as oficinas tinha experiência com a População em Situação de Rua, mas já houveram participado de outras ações sociais com público em vulnerabilidade. Mesmo tendo experiência com grupos que vivem em extrema pobreza, esses profissionais relataram que a População em Situação de Rua é um grupo completamente diferente de qualquer outro que já haviam trabalhado, pois os alunos, por viverem nas ruas, possuem outra forma de administrar as horas do dia, não chegando às aulas nos horários estabelecidos e, muitas vezes, apresentando-se às aulas sem condições de participação, pelo uso de álcool ou de outras drogas, ou até mesmo por justos motivos, como a necessidade de atendimento: psicológico; em relação a algum benefício social; relativo ao programa Bolsa Família, alusivo ao programa Auxílio Vulnerabilidade; etc. Foi relatada a importância das reuniões mensais entre a equipe do Projeto Equinócios e Centro POP Brasília, para se discutir o andamento das aulas e a relação dentre todos os envolvidos, bem como para compreender melhor o funcionamento da relação entre o Estado e Sociedade.

Segundo Hino et al. (2018) há uma necessidade da formação de pessoas com habilidades e competências para trabalhar com as particularidades dos modos de vida e das necessidades da população em situação de rua. Essa formação deve acontecer em cursos de capacitação e também deve ser inserida nas instituições de ensino superior em extensões ou de forma transversal nas disciplinas, para promover o atendimento equânime desse grupo específico, buscando adequar o atendimento prestado a realidade vivenciada.

Durante o Projeto Equinócios, dois dos oficineiros entrevistados disseram que tiveram objetos pessoais furtados dentro da unidade de atendimento, sem manifestarem suspeita de origem de autoria. Um deles relatou que sabia das regras de segurança e que deveria ter 
deixado o pertence furtado no local designado para a guarda de objetos pessoais de valor. O outro alegou ter sido falta de cuidado do Centro POP Brasília e do Projeto Equinócios para com ele, e disse que se sentia prejudicado com tal acontecimento.

Questões como essas evidenciam a necessidade de uma capacitação prévia dos profissionais que irão realizar algum trabalho com a População em Situação de Rua e a importância de as equipes de trabalho se reunirem periodicamente para discutir o andamento das oficinas. Segundo Gatti e Pereira (2011), apesar do avanço das políticas públicas direcionadas à População em Situação de Rua, ainda se faz necessário discutir-se o atendimento dessa população em vulnerabilidade entre os profissionais de atendimento, pois estes ainda não são adequadamente capacitados. $\mathrm{O}$ atendimento genérico e superficial da População em Situação de Rua é problema antigo, dentro da rede socioassistencial pública, cujas causas se identificam na escassa oferta de capacitação e de formação técnica aos profissionais que atuam nessas políticas, seja em CREAS, seja em Centro POP.

A insalubridade ambiental e os riscos enfrentados pelos que trabalham com público em extrema vulnerabilidade contribuem para que os atendimentos sejam seletivos, discriminatórios. Sob tais condições, pessoas em situação de rua com perfis diferenciados e demandas específicas são submetidas a metodologias padrão de atendimento ou escanteadas.

Com relação à População em Situação de Rua, foram alcançadas as 20 entrevistas previstas. Os entrevistados demonstraram acreditar que o Centro POP Brasília é um espaço de garantia de "Direitos" e o principal espaço de convivência daqueles que vivem nas ruas de Brasília. Relataram ser esse um espaço onde encontram amizade e carinho, ou seja, o lar de quem não tem um. Assim, corroboraram com a destinação formal do espaço, já que o Centro POP Brasília se caracteriza como uma unidade de referência da Proteção Social
Especial - PSE de média complexidade, de natureza pública e estatal, como um espaço de garantia de "Direitos".

Sendo Brasília uma cidade funcional, concebida com separação das áreas de lazer, de trabalho e de moradia, dentro das hoje ultrapassadas ideias do arquiteto francês Le Corbusier, há acentuado "aumento da segregação espacial e a discriminação contra pessoas sem direito à cidade", principais motivos de ida às ruas, na Capital federal (Gatti \& Pereira, 2011, p.15).

Segundo dados coletados nas entrevistas semiestruturadas, dentre os contemplados (pessoas em situação de rua) pelo Projeto Equinócios, 10 dos entrevistados afirmaram que, apesar da invisibilidade da População em Situação de Rua, sentiam-se bem em relação ao comportamento de descaso advindo dos habitantes das quadras residenciais de Brasília, pois entendiam ser melhor não serem vistos, para não serem punidos ou molestados por viverem nas ruas. No âmbito da saúde, pôde-se reconhecer as conquistas dessa população no que tange à participação social, através das ações do Movimento Nacional da População em Situação de Rua na construção das Políticas de Saúde.

Em 2014, o Ministério da Saúde lançou uma cartilha com proposta de promoção da saúde, criando um material educativo e informativo que aborda a importância da participação social na efetivação dos direitos da cidadania e, também, que sensibiliza gestores e profissionais de saúde. Surgiu, então, o plano operativo para implementação de ações de saúde para a População em Situação de Rua, onde se destacam os seguintes eixos: (1) inclusão da População em situação de Rua no escopo das redes de atenção à saúde, das quais faz parte o "Consultório na Rua", que oferece a garantia de acesso à saúde; a atenção domiciliar e em espaços de acolhimento institucional; e a capacitação das equipes de urgência; (2) promoção e vigilância em saúde, com ações que visam intensificar a busca ativa $\mathrm{e}$ tratamentos supervisionados, assim como reduzir e controlar a incidência de tuberculose, 
DST/AIDS e agravos recorrentes, na população em questão; (3) educação permanente em saúde, na abordagem da População em Situação de Rua, ações essas que se propõem a promover a capacitação e a sensibilização dos profissionais de saúde, para atendimento à População em Situação de Rua; (4) fortalecimento da participação e do controle social por meio de apoio e da sensibilização de lideranças no Movimento Social da PSR, com a finalidade de articular e de fomentar com gestores estaduais e municipais, a capacitação de conselheiros de saúde sobre a temática Saúde da População em Situação de Rua; (5) monitoramento e avaliação das ações de saúde para População em Situação de Rua.

Tais ações visam diminuir a dificuldade de acesso da População em Situação de Rua aos serviços de saúde. Ressalte-se que, dentre os moradores de rua entrevistados: 12 procuram o "Consultório na Rua" quando não se sentem bem; 4 (quatro) buscam ajuda em hospital ou posto de saúde, e usam o álcool ou outras drogas para não sentirem dor; 2 não fazem nada para aliviar o sofrimento físico; e os outros 2 não responderam à pergunta. $\mathrm{O}$ "Consultório na Rua” do Plano Piloto, Brasília -DF, localiza-se no Cento POP Brasília, mas realiza abordagens nas ruas e visita as casas daqueles que saíram das ruas e que ainda necessitam de cuidados relacionados a tuberculose, DST/AIDS e agravos recorrentes dessa.

Quando perguntados sobre as oficinas do Projeto Equinócios, os usuários entrevistados as citaram como espaços de troca e de aprendizagem e como uma oportunidade de redução de seus danos. Segundo Conte et al. (2004), a Política de Redução de Danos é uma estratégia de saúde pública que busca minimizar as consequências adversas da exclusão social, mormente do consumo de drogas. Para aqueles que já são usuários e dependentes de drogas, deve-se lhes oferecer meios para que possam rever essa relação de dependência. Incluir as pessoas que fazem uso de substâncias psicoativas em atividades artísticas, fortalece suas redes socioafetivas e promove a autoestima, que são formas de redução de danos.
[...] antes eu usava crack da hora de acordar até a hora de dormir. Se não dormia, era o dia inteiro e a noite também. Agora, tenho um monte de coisas pra fazer, aqui no Centro POP. É oficina disso e daquilo, cheio de gente feliz. Só uso crack à noite, quando estou na solidão das ruas, eu e eu [...]. (Relato de um dos alunos das oficinas do Projeto Equinócios. Janeiro 2016).

De acordo com os dados coletados na entrevista qualitativa, pôde-se perceber que são diversos os motivos que levaram os entrevistados a viverem nas ruas: uso de álcool, uso de outras drogas, desavenças familiares. Segundo a Silva (2006), o problema também está relacionado ao fato de não terem uma casa própria ou dinheiro para pagarem aluguel, agravado com o fato de que a falta de renda e oportunidades de trabalho podem levar ao adoecimento físico e mental. Mais uma vez, o que se percebe é a falta de recursos públicos para a recuperação ou minimização das agruras de uma população não resiliente ou conformada com suas adversidades.

Em relação às três oficinas implementadas no decorrer desse projeto e que se realizaram no Centro POP Brasília: oficina de agroecologia; oficina de arte gráfica de rua (estêncil, mural e grafite); e oficina de fotografia e formação de memória imagética; foi observado que, das 20 pessoas que dessas oficinas participaram, a sua maioria nascidas no Distrito Federal, 18 eram homens e 2 eram mulheres.

Segundo Gatti e Pereira (2011), critérios rígidos são exigidos para a elegibilidade, interferindo diretamente no direito de acessar os benefícios socioassistenciais existentes, o que fortalece a exclusão de uma grande parte da População em Situação de Rua, que não consegue frequentar, sequer se matricular em escolas, e realizar acompanhamentos médicos, já que "ambas as políticas, de Educação e de Saúde, falham no atendimento a indivíduos sem documentação, 
endereço fixo e cidadania". (Gatti \& Pereira, 2011, p. 167).

Sobre as oficinas terapêuticas/artísticas implementadas pelo Projeto Equinócios, a de fotografia foi frequentada por $43 \%$ dos usuários entrevistados, sendo a oficina com menor índice de evasão. O principal motivo citado por participantes $(27 \%)$ dessa oficina, para o sucesso dela, foi à possibilidade de resgate de suas identidades, facultando-lhes a oportunidade de se verem com "outros olhos".

A pessoa que vive em situação de rua acaba perdendo seus direitos sociais e civis, uma vez que sofre uma gradativa exclusão social. A constante falta de perspectiva abaixa a autoestima. Promover ações de resgate ao convívio social possibilita a reconstrução da identidade social do indivíduo (Carmo \& Guizardi, 2018).

Em decorrência de greve dos servidores do Centro POP Brasília, a oficina de fotografia, durante o mês de novembro de 2015, passou a acontecer em um espaço cedido pelo Museu da República, em parceria com a Revista Traços Brasília - DF. Além de propiciar o resgate da identidade das pessoas em situação de rua participantes, através da fotografia, outra estratégia adotada foi a de proporcionar a essas pessoas, por intermédio do manuseio personalizado de câmaras fotográficas, seus desenvolvimentos artísticos e negociais, haja vista as fotografias que elas próprias tiraram, de acordo com suas concepções e perspectivas, selecionadas e mostradas em exposições de arte com o apoio da Revista Traços, podiam ser vistas com grande publicidade, inclusive com a participação desses novos artistas, que também podiam comprar exemplares da referida edição da Revista Traços, a preços simbólicos, e as revender nas ruas, com lucro, dotados de até de melhor capacidade argumentativa e comercial.

As fotografias desses novos artistas também foram impressas em cartões postais financiados pela sociedade e pela ONG ATADOS Brasília, como mais uma forma de geração de renda para tal população.
Essas parcerias trouxeram visibilidade para as pessoas em situação de rua participantes, pois elas passaram a se apropriar da cidade e de si mesmo e a trabalharem empoderadas, já que experienciaram, através das oficinas do Projeto Equinócios, o produto que passaram a comercializar: a edição da Revista Traços - Brasília, DF, com matéria sobre eles e suas artes, pelo qual recebem o título de porta-vozes da Cultura; e seus cartões postais.

A oficina de fotografia trouxe aos usuários do Centro POP Brasília a possibilidade de transitarem por ambientes frequentados pela sociedade da qual se apartaram, proporcionando-lhes tratamento em pé de igualdade. A visibilidade disponibilizada por essa oficina à população em situação de rua propiciou-lhes convites para exporem suas fotografias: no Museu da República, em novembro de 2015; na $15^{\mathrm{a}}$ Conferência Nacional de Saúde, em dezembro de 2015; no Centro POP Brasília, em dezembro de 2015; no teatro Dulcina, em Brasília, DF, em abril de 2016; e no Metrô DF, em maio de 2016. Essas exposições foram intituladas pelos próprios alunos (pessoas em situação de rua), como Exposição Rua em Foco: para quem vive fora do foco.

De acordo com a Política Nacional para inclusão da População em Situação de Rua (Brasil, 2008a), o desenvolvimento de ações intersetoriais, objetivando a reintegração dessas pessoas à comunidade, é condição para o acesso pleno dessa clientela aos seus direitos de cidadãos, por intermédio do desenvolvimento social. A intersetorialidade aqui é entendida como as formas de realização de serviços, com articulações de saberes e fazeres, planejamentos, intervenções e avaliações, com envolvimento do Estado e da sociedade, prática vivenciada no decorrer do projeto, com a realização da oficina de fotografia.

A oficina de agroecologia foi frequentada pelos 20 entrevistados e citada como a mais importante, no que tange à possibilidade de se aperfeiçoar e de encontrar um ofício no futuro. Nesse caso, os 
entrevistados argumentaram que o trabalho na horta, além de terapêutico, proporcionou $\mathrm{o}$ resgate de boas lembranças/memórias da infância.

A partir da oficina de agroecologia, quatro (4) dos entrevistados foram contratados por intermédio do Projeto Cuidando da Quadra, organizado por Prefeitura de Quadra da Asa Sul, Brasília, DF, em parceria com o Centro POP Brasília, que é uma iniciativa de um grupo de moradores da Asa Sul e que tem como objetivo a geração de oportunidades de trabalho e renda para pessoas em situação de rua, a partir de serviços básicos (jardinagem, limpeza da quadra), demandados por moradores, comerciantes e associações comunitárias do Plano Piloto de Brasília. Esse projeto promove uma visão social que envolve o estabelecimento de parcerias entre o setor público, o privado e a sociedade, apresentando uma proposta que visa possibilitar melhor qualidade de vida para as pessoas em situação de rua. Além disso, abrange vários outros aspectos, como as questões relacionadas à segurança pública e à vulnerabilidade social.

Garcez Ghirardi, Lopes, Barros e Galvani (2012) afirmam que a participação social é ampliada à medida em que a dimensão do trabalho é abordada, pois não se trata de um processo de reabilitação da força de trabalho da População em Situação de Rua, mas sim do direito social da garantia do acesso ao trabalho, não como obrigação, mais como parte de uma vida em sociedade.

Em relação à oficina de artes gráficas, os usuários citaram-na como a mais divertida. Não visualizaram nenhuma possibilidade de renda através dela, mas aduziram que as habilidades dela adquiridas lhes possibilitariam almejar a revitalização do Centro POP Brasília por intermédio de grafitamento de suas paredes, com arte e inserção de frases de impacto, por suas próprias mãos, objetivando tornar esse espaço em um ambiente mais aconchegante.

Segundo Ministério da Saúde (Brasil, 2012), ações como: grupos de apoio, terapia comunitária, práticas integrativas e complementares (Yoga, Aikidô, horticultura, fotografia), arte terapia e apoio psicológico, individual ou em grupo, propiciam suporte emocional e construção de resiliência na População em Situação de Rua. Assim, pôde-se observar que o Projeto Equinócios melhorou a qualidade de vida da população alvo, promovendo a Saúde.

Nos meses de acompanhamento (outubro 2015 a junho 2016) do Projeto Equinócios, constatou-se que a ação proposta nesse projeto, por ser realizada de modo integrado e com a participação ativa de pessoas em situação de rua, sociedade e Governo, apresentou índices baixíssimos de evasão. Apesar de as oficinas terem sido frequentadas por mais de setenta (70) alunos, observou-se a permanência de específicos dezessete (17) nos três (3) diferentes tipos de oficinas, do começo ao fim das atividades. Dos vinte (20) alunos entrevistados, dezessete (17) permaneceram do início ao fim das oficinas artísticas e ambientais. Os outros (3) entrevistados participaram de apenas (2) das oficinas propostas.

Por ser a População em Situação de Rua classificada como um grupo social "flutuante" (Botti et. al., 2009, p.164) e instável, considerara-se a suposição de que, no decorrer do Projeto Equinócios, haveria evasão por parte dos beneficiados pelas oficinas (pessoas em situação de rua), ou seja, que o grupo que estaria ao final de um ano de oficinas não seria o mesmo que as iniciara. Acreditava-se, porém, que as evasões em outras experiências do Centro POP Brasília para esse público decorreram de suas rejeições, por não terem sido construídas para efetivamente integrar os componentes desse público na sociedade, apresentando perspectivas profissionalizantes. Assim, imaginou-se que a ação proposta pelo Projeto Equinócios, por ser realizada de modo integrado, tivesse maior participação e envolvimento. Essa tese foi verificada ao longo do andamento do projeto, em cada uma de suas etapas, e pôde-se constatar que é possível haver uma mudança efetiva em relação aos direitos da população em vulnerabilidade, se houver 
esforço mútuo entre as instituições públicas e a sociedade.

Em relação às observações em campo e diário de campo, analisados, foi constatado que um dos principais motivos pelos quais os usuários do Centro POP Brasília não estavam frequentando as oficinas assiduamente era por que, terça-feira, também era o dia em que as assistentes sociais organizavam um evento paralelo para um grande grupo de usuários, para lhes explicar sobre os benefícios oferecidos pelo SUAS. Para que não houvesse evasão nas oficinas, foi discutido e decidido em uma das reuniões junto ao Centro POP Brasília, que essa reunião sobre o SUAS poderia ser realizada em horários diferentes daqueles nos quais as oficinas ocorriam.

Durante todo acompanhamento do Projeto Equinócios foi possível perceber a construção coletiva dos envolvidos: população em situação de rua; servidores do Centro POP Brasília; e equipe do Projeto Equinócios.

Os relatos feitos pelos profissionais, tanto da equipe do Centro POP Brasília quanto dos oficineiros do Projeto Equinócios, nas reuniões de grupo, sob autorização deles, foram pontuados para que, ao se analisar os formulários, servissem de subsídio para balizamento da compilação dos dados coletados da forma mais fidedigna possível, mantendo a identidade dos sujeitos citados em sigilo.

Em relação aos professores contratados para ministrar as oficinas no Centro POP Brasília, percebeu-se a necessidade de os reunir mensalmente com a equipe do Centro POP Brasília, para discussão, avaliação e troca das experiências vividas. Essa necessidade se deu em face de os oficineiros, apesar de terem tido uma capacitação prévia em relação às regras e condutas de convivência no Centro POP Brasília, muitas vezes se frustravam por não saberem lidar com casos de desinteresse dos alunos ou por terem programado com esmero uma aula que, ministrada, transcorreu de forma não esperada.
Durante a pesquisa, no início da implementação das oficinas terapêuticas e artísticas, os professores se queixaram bastante nas reuniões, por não saberem improvisar para que os alunos mantivessem a atenção e o entusiasmo nas aulas. Para que os professores não se sentissem frustrados e para que os alunos não se evadissem das oficinas, as aulas foram construídas com a participação efetiva dos alunos. Foram propostas aos alunos, possibilidades em relação aos temas a serem discutidos em cada oficina, e fez-se, então, um planejamento em conjunto. Apesar de essa abertura por parte dos professores ter considerada pela equipe de profissionais do Centro POP Brasília uma construção coletiva, para que não houvesse significativa evasões, a equipe do Projeto Equinócios teve que se reinventar diariamente, num constante processo de replanejamento. Mais uma vez, destaca-se aqui a importância de em projetos como esse, de longo prazo, de se realizar com cautela uma seleção, acompanhada por psicólogos, de profissionais "oficineiros" que possuam perfil para esse tipo de trabalho, assim como oferecer-lhes capacitação prévia e continuada e proporcionar espaços para trocas de ideias (estudo de casos).

Constata-se que, para o sucesso de um projeto de cunho sócio artístico e cultural, é necessário um esforço conjunto das instituições públicas e da sociedade, a fim do desenvolvimento de estratégias integradas e multidisciplinares. E é nesse contexto que o Projeto Equinócios se agrega à Política Pública (Brasil, 2013). Selecionar profissionais capacitados, oferecer-lhes um espaço de troca e aprendizado e construir atividades junto à População em Situação de Rua, são fatores essenciais para o êxito da implementação de atividades artísticas dentro de uma unidade de referência que trabalha com tal população, sendo imprescindível se compreender o público alvo e respeitá-lo como cidadãos.

\section{Considerações finais}

O Projeto Equinócios, atividades em comunidade, surgiu como uma proposta para a ressignificação dos espaços públicos, o resgate 
da população em situação de rua ao convívio social e a promoção da Saúde.

Partindo-se do nome que a própria população em situação de rua deu às exposições artísticas promovidas: "Rua em Foco: para quem vive fora do foco", observa-se a percepção auto reflexiva desse grupo, que se sente fora do contexto social e anseia por integração. O Projeto Equinócios foi relevante em questões diretamente relacionadas ao empoderamento da população de rua, pois estimulou a criação de vínculos de colaboração e de solidariedade entre essa população e o restante da comunidade brasiliense, promovendo o aprimoramento das vivências comunitárias e do sentimento de pertencimento mútuo, contribuindo diretamente para uma possível redução de danos aos usuários de substâncias psicoativas, álcool e outras drogas, frequentadores do Centro POP Brasília.

Em face de essas exposições fotoartísticas terem estimulado a autoestima desses novos artistas, ficou comprovado o papel da arte na ressocialização da população em situação de rua. Alinha-se a esse fato o manifesto desejo de grafitagem e de outros embelezamentos artísticos, ratificando a mesma tese.

As oficinas de agroecologia e fotografia, além das habilidades laborativas, desenvolveram o interesse econômico e comercial, respectivamente, na medida em que as atividades agrícolas propiciaram emprego e as artísticas, comercialização negocial. Elas também promoveram a aproximação das pessoas em situação de rua com a comunidade brasiliense, reduzindo os preconceitos $\mathrm{e}$ potenciais conflitos entre esses grupos.

Ao caracterizar os desafios enfrentados no cotidiano do trabalho desenvolvido junto à população em situação de rua, faz-se necessário o cumprimento das diretrizes da Política Nacional para a População em Situação de Rua, bem como o suprimento de recursos orçamentários em níveis adequados. Também deve ser implementada uma política de formação e capacitação continuada dos profissionais que se propõem a atuar e dos que já atuam junto às pessoas em situação de rua. A sociedade, por intermédio de diversos de seus segmentos (universidades, ONGs, governos), deve propugnar para que as políticas existentes sejam plenamente cumpridas e aprimoradas e que novas políticas sejam desenvolvidas e efetivamente aplicadas, em prol da População em Situação de Rua.

No que tange à Saúde, o Projeto Equinócios desenvolveu o autocuidado e o desejo a melhores condições de saúde, tanto que se verificou a redução de danos dos usuários dos pesquisados e a maior procura pelos serviços de saúde, não apenas em crises, mas sobretudo nos acompanhamentos rotineiros.

A integração da população em situação de rua de Brasília com a sociedade civil, por meio de projetos sociais como Equinócios, evidenciou a importância de investimento público nesses espaços, o que pode ser visto por meio da Secretaria de Cultura do GDF, que a partir de 2017 passou a integrar Editais Públicos de Cultura, com linhas específicas para ações dentro dos Centros de Referências Especializados. Após o término do financiamento do Projeto Equinócios em 2017, a oficina de agroecologia e outras duas oficinas criadas após o período da pesquisa: gastronomia da horta e música, continuaram a acontecer no Centro POP Brasília com a atuação dos próprios servidores e de outras instituições civis, o que mostra o êxito do projeto retratado.

\section{Referências}

Akerman, M., Franco de Sá, R., Moyses, S., Rezende, R., \& Rocha, D. (2014).

Intersetorialidade? IntersetorialidadeS!.
Ciência \& Saúde Coletiva, 19(11), 4291-

4300. doi: 10.1590/1413-

$\underline{812320141911.10692014}$ 
Botti, N. C. L, Castro, A. G., Ferreira, M., Silva, A. K., Oliveira, L. C., Castro, A. C. H. O., \& Fonseca, L. L. K. (2009).

Condições de saúde da população de rua da cidade de Belo Horizonte. Cadernos Brasileiros de Saúde Mental, 1(2), 162176. Recuperado de https://periodicos.ufsc.br/index.php/cbsm/ar ticle/view/68482

Bonalume, C. R. (2011). O paradigma da intersetorialidade nas políticas públicas de esporte e lazer. LICERE - Revista Do Programa De Pós-graduação Interdisciplinar Em Estudos Do Lazer, 14(1). doi: 10.35699/1981-3171.2011.782

Brasil. (2008a). Política Nacional para inclusão social da População em situação de rua. Recuperado de http://www.recife.pe.gov.br/noticias/arquiv os/2297.pdf

Brasil. Ministério do Desenvolvimento Social e Combate à Fome. (2008b). Pesquisa Nacional sobre a População em Situação de Rua. Brasilia/DF: MDS. Recuperado de https://fpabramo.org.br/acervosocial/wpcontent/uploads/sites/7/2017/08/033.pdf

Brasil. (2011a). Programa Providência de Elevação da Renda Familiar. Relatório Anual 2011. Recuperado de https://programaprovidencia.org.br/relatori os-anuais/

Brasil. Ministério do Desenvolvimento Social e Combate à Fome. (2011b). Orientações Técnicas: Centro de Referência Especializado para População em Situação de Rua - Centro Pop (SUAS e População em Situação de Rua, Volume 3). Brasília: Gráfica e Editora Brasil LTDA.

Brasil. Ministério da Saúde. (2012). Manual sobre o cuidado à saúde junto a população em situação de rua. Brasília/DF: Ministério da Saúde. Recuperado de http://189.28.128.100/dab/docs/publicacoes /geral/manual_cuidado_populalcao_rua.pdf

Brasil. Ministério do Desenvolvimento Social e Combate à Fome. (2013a). Implicações do SUAS e da Gestão Descentralizada na Atuação dos Conselhos de Assistência Social (Cartilha SUAS 2). Recuperado de https://fpabramo.org.br/acervosocial/wpcontent/uploads/sites/7/2017/08/129.pdf

Brasil. Secretaria de Direitos Humanos da

Presidência da República. (2013b).

Diálogos sobre a população em situação de rua no Brasil e na Europa: experiências do Distrito Federal, Paris e Londres. Brasília/DF: SDH. Recuperado de http://sectordialogues.org/sites/default/files/ acoes/documentos/publicacao_dialogos_so bre_a_populacao_em_situacao_de_rua_no_ brasil_e_na_europa.pdf

Brasil. Ministério da Saúde. (2014). Saúde da População em situação de rua: um direito humano. Brasília/DF: Ministério da Saúde. Recuperado de http://bvsms.saude.gov.br/bvs/publicacoes/s aude_populacao_situacao_rua.pdf

Brisola, E. M. (2016). O Assistente Social como trabalhador na Política de Assistência Social. Serviço Social em Revista, 19(1), 0523. doi: 10.5433/1679-4842.2016v19n1p05

Carmo, M. E., \& Guizardi, F. L. (2018) O conceito de vulnerabilidade e seus sentidos para as políticas públicas de saúde e assistência social. Cad. Saúde Pública, 34(3):e00101417. Recuperado de https://www.scielo.br/pdf/csp/v34n3/16784464-csp-34-03-e00101417

Conte, M., Reverbel, C., Sbruzzi, C., Menezes, C. B., Alves, G. T., Queiroz, R., \& Braga, P. (2004) Redução de Danos e Saúde Mental na Perspectiva da Atenção Básica. Boletim Saúde, 18(1), 59-77. Recuperado de http://www.boletimdasaude.rs.gov.br/conte udo/1272/reducao-de-danos-e-saudemental-na-perspectiva-da-atencao-basica

Decreto $n^{o}$ 7.053, de 23 de dezembro de 2009. Institui a Política Nacional para a População em Situação de Rua e seu Comitê Intersetorial de Acompanhamento e Monitoramento, e dá outras providências. Recuperado http://www.planalto.gov.br/ccivil_03/_Ato2 007-2010/2009/Decreto/D7053.htm

Departamento Nacional de Trânsito [DENATRAN]. (2015). Frota. Recuperado de http://www.denatran.gov.br/frota.htm

Escorel, S. (1999). Exclusão social: em busca de uma categoria. In S. Escorel, Vidas ao 
léu: trajetórias de exclusão social (pp. 2381). Rio de Janeiro: Editora FIOCRUZ.

Frangella, S. M. (2009). Corpos urbanos errantes: uma etnografia da corporalidade de moradores de rua em São Paulo (1a. ed.). São Paulo: Anna Blume/Fapesp.

Gama C. A. P., Campos, R. T. O., \& Ferrer A. L. (2014). Saúde mental e vulnerabilidade social: a direção do tratamento. Revista Latinoamericana de Psicopatologia Fundamental, 17(1), 69-84. doi: 10.1590/S1415-47142014000100006

Gatti, B. P., \& Pereira, C. P. (Orgs.). (2011). Projeto Renovando a Cidadania: Pesquisa sobre a população em situação de rua do Distrito Federal. Brasília: Gráfica Executiva.

Garcez Ghirardi, M. I., Lopes, S. R., Barros, D. D., \& Galvani, D. (2005). Vida na rua e cooperativismo: transitando pela produção de valores. Interface - Comunicação, Saúde, Educação, 9(18), 601-610. doi: 10.1590/S1414-32832005000300014

Hino, P., Santos, J. O., \& Rosa, A. S. (2018). Pessoas que vivenciam situação de rua sob o olhar da saúde. Revista Brasileira de Enfermagem, 71(Supl.1), 684-692. doi: 10.1590/0034-7167-2017-0547

Lei $n^{\circ}$ 8.742, de 7 de dezembro de 1993. Dispõe sobre a organização da Assistência Social e dá outras providências. Recuperado de http://www.planalto.gov.br/ccivil_03/leis/18 742compilado.htm

Mattos, R. M., \& Ferreira, R. F. (2004). Quem vocês pensam que (elas) são? Representações sobre as pessoas em situação de rua. Psicologia \& Sociedade, 16(2), 47-58. doi: 10.1590/S010271822004000200007

Moniz, A. L. F. (2014). Voluntariado ambiental como síntese dos comportamentos pró-sociais e próambientais: uma abordagem empírica pelo modelo processual (Tese de Doutorado). Instituto de Psicologia, Universidade de Brasília-UNB, Brasília/DF.
Paiva, I. K. S., Lira, C. D. G., Justino, J. M. R., Miranda, M. G. O., \& Saraiva, A. K. M. (2016). Direito à saúde da população em situação de rua: reflexões sobre a problemática. Ciência \& Saúde Coletiva, 21(8), 2595-2606. doi: 10.1590/141381232015218.06892015

Pereira, C. P. (2008). Rua sem Saída: um estudo sobre as relações entre o Estado e a População de Rua de Brasília (Dissertação de Mestrado). Universidade de Brasília, Brasília/DF.

Pontes, A. C. S. J. E. (2009). Os serviços públicos de saúde e o atendimento à população de rua do Distrito Federal: uma realidade precária (Monografia de Bacharelado). Universidade de Brasília, Brasília/DF.

Sánchez, A. I. M., \& Bertolozzi, M. R. (2007). Pode o conceito de vulnerabilidade apoiar a construção do conhecimento em Saúde Coletiva?. Ciência \& Saúde Coletiva, 12(2), 319-324. doi: 10.1590/S141381232007000200007

Silva, M. L. L. (2006). Mudanças recentes no mundo do trabalho e o fenômeno população em situação de rua no Brasil 1995-2005 (Dissertação de mestrado). Universidade de Brasília, Brasília/DF. Recuperado de http://repositorio.unb.br/bitstream/10482/17 63/1/2006_Maria\%20Lucia\%20Lopes\%20 da\%20silva.pdf

Vitoriano, I. S. (2011). A ação da rede socioassistencial: quais as possibilidades desta efetivar-se? In $V$ Jornada Internacional de Políticas Públicas (s.p). São Luis, Maranhão/Brasil: Universidade Federal do Maranhão. Recuperado de http://www.joinpp.ufma.br/jornadas/joinpp 2011/CdVjornada/jornada_eixo_2011/impa sses_e_desafios_das_politicas_da_segurida de_social/a_acao_da_rede_socioassistencia 1_quais_as_possibilidades_desta_efetivarse. pdf 


\section{Dados sobre as autoras:}

- Juliana Sangoi: Psicóloga, graduada pelo Centro Universitário do Distrito Federal (2018), Publicitária pela Universidade do Sul de Santa Catarina UNISUL (2006). Atuou como colaboradora do Projeto Fazendo Minha História com crianças em condições de vulnerabilidade nas Aldeias Infantis SOS Brasil. Atualmente trabalha como Assessora em Migração e Refúgio e é pesquisadora do Centro Universitário do Distrito Federal - UDF.

- André Luís Ferreira Moniz: Psicólogo (1999), mestre e doutor em Psicologia pela Universidade de Brasília (2002 e 2014). Atuou como coordenador em cursos de Psicologia e como professor e pesquisador nas áreas de Psicologia da Saúde, Psicologia Social e Ambiental. Atualmente é professor do Centro Universitário do Distrito Federal - UDF.

- Carolina Conceição Prado: Psicóloga pelo Centro Universitário de Brasília (2001), Bacharela e licenciada em Ciências Biológicas pela Universidade de Brasília (2003 e 2004). Especialista em Educação e promoção da saúde (2004), em Gestão de Sistemas e Serviços de Saúde (2008) e Mestre em Ciências da Saúde pela Universidade de Brasília (2005). Atualmente é professora e pesquisadora do Centro Universitário do Distrito Federal - UDF. 